\title{
Astilbin reduces ROS accumulation and VEGF expression through Nrf2 in psoriasis-like skin disease
}

Wuyuntana Wang ${ }^{1,2}$, Yuhai $^{3}$, Huan Wang $^{1}$, Chasuna ${ }^{1}$ and Bagenna ${ }^{1 *}$

\begin{abstract}
Background: Psoriasis is a common and intractable skin disease affecting the physical and mental health of patients. The accumulation of ROS is involved in the pathogenesis of psoriasis and antioxidants are believed to be therapeutic. This study aimed to investigate the therapeutic efficacy of astilbin on ROS accumulation in psoriasis.

Results: The study showed that $50 \mathrm{\mu g} / \mathrm{ml}$ astilbin could inhibit the growth and reduce the accumulation of ROS in $\mathrm{HaCaT}$ cells stimulated by IL-17 and TNF-a. Astilbin could elevate the Nrf2 accumulation in the nuclei, eventually leading to the transcriptional activation of various antioxidant proteins and reducing the expression of VEGF.
\end{abstract}

Conclusions: Our results collectively suggest that astilbin could induce Nrf2 nucleus translocation, which is contribute to reduce the ROS accumulation and VEGF expression, and inhibit the proliferation of HaCaT cells.

Keywords: Astilbin, ROS, Nrf2, Psoriasis

\section{Background}

Psoriasis is a chronic inflammatory dermatosis that occurs in approximately $2 \%$ of adults worldwide [1]. Psoriasis can cause itching with appearing the silvery white scales and raised erythema, and can lead to depressive illness as comorbidity [2], which means patients may suffer both physically and mentally with psoriatic. Psoriasis is also associated with many diseases like hypertension, diabetes mellitus and the metabolic syndrome [3-5]. Apart from the abnormal interconnected networks between immune cells and various inflammatory cytokines, we can also find the pathological features with increased proliferation, aberrant differentiation and impaired apoptosis of keratinocytes in psoriasis lesions [6].

The release of reactive oxygen species (ROS) is regarded as a pro-inflammatory factor, which can induce inflammatory cytokines releasing, DNA modification and oxidative damage $[7,8]$. The overproduction of ROS

\footnotetext{
*Correspondence: bagenna@126.com

${ }^{1}$ Department of Mongolian Pharmacy, School of Mongol Medicine, Inner Mongolia University for Nationalities, 536 West of Huolinhe Street,

Tongliao 028000, Inner Mongolia, People's Republic of China

Full list of author information is available at the end of the article
}

and deficient function of antioxidant system activities are involved in the pathogenesis of psoriasis, therefore alterations of antioxidants are associated with psoriasis and antioxidants are believed to be therapeutic [9-11]. In addition, it is demonstrated that oxidative stress may activate mechanisms that restore the redox balance including activation of the Nrf2, a transcription factor which plays an important role in antioxidant and cyto-protective gene transcription $[12,13]$. However, the expression and the activity of Nrf2 in the skin of psoriatic patients were discordant in several studies $[10,14,15]$, the mechanisms of Nrf2 regulation in psoriasis are urgently needed to be elucidated.

Astilbin, is a major bioactive compound extracted from Rhizoma Smilacis glabrae (RSG), as a kind of medicinal herb, that is used to treat autoimmune diseases in traditional Chinese medical science [16-18]. Recent researches suggests that astilbin has multiple clinicallyrelevant bioactivities, including anti-inflammatory [1820], antioxidant [19, 21], and anti-tumor effects [22]. However, as a well-known antioxidant, the effects and the mechanisms of astilbin on psoriasis remain largely elusive. 
The aim of the present study was to investigate the therapeutic efficacy of astilbin in psoriasis. We examined the potential effects of astilbin on ROS accumulation and further demonstrated its correlation with the expression and activation of Nrf2, by using an immortalized human keratinocyte cell line $\mathrm{HaCaT}$ as cellular model of psoriasis [23, 24].

\section{Results}

\section{Astilbin inhibits the proliferation and reduces ROS} generation in $\mathrm{HaCaT}$ cells

To investigate the effect of astilbin on cell growth in $\mathrm{HaCaT}$ cell lines, we initially stimulated $\mathrm{HaCaT}$ cells with IL-17 and TNF- $\alpha$, the pro-inflammatory cytokines which may contribute to the pathophysiology of psoriasis. Cell growth was monitored by high-content screening (HCS) at day1, day3 and day5. As expected, IL-17 and TNF- $\alpha$ could significantly increase the proliferation of $\mathrm{HaCaT}$ cells at day5 (Fig. 1a, b). Treatment with astilbin at $50 \mu \mathrm{g} / \mathrm{ml}$ was introduced at day2, and proliferation changes were observed at day5. The growth curves detected by HCS showed that astilbin treatment dramatically decreased the growth of $\mathrm{HaCaT}$ keratinocytes stimulated with IL-17 and TNF- $\alpha(\mathrm{P}<0.001)$, and also in the control group $(\mathrm{P}<0.05)$ (Fig. 1a, b). Since ROS-induced oxidative damage is regarded as a critical mediator in the development of psoriasis, we next examined the effect of astilbin treatment on the accumulation of ROS in HaCaT cells by DCFH-DA staining. As shown in Fig. 1c, IL-17 and TNF- $\alpha$ were able to stimulate ROS generation significantly, however, astilbin treatment resulted in significant reduction of the ROS levels. In addition, astilbin also reduced the ROS production in control group. These results suggested that astilbin could inhibit the growth and reduce the accumulation of $\mathrm{ROS}$ in $\mathrm{HaCaT}$ keratinocytes stimulated by IL-17 and TNF- $\alpha$.

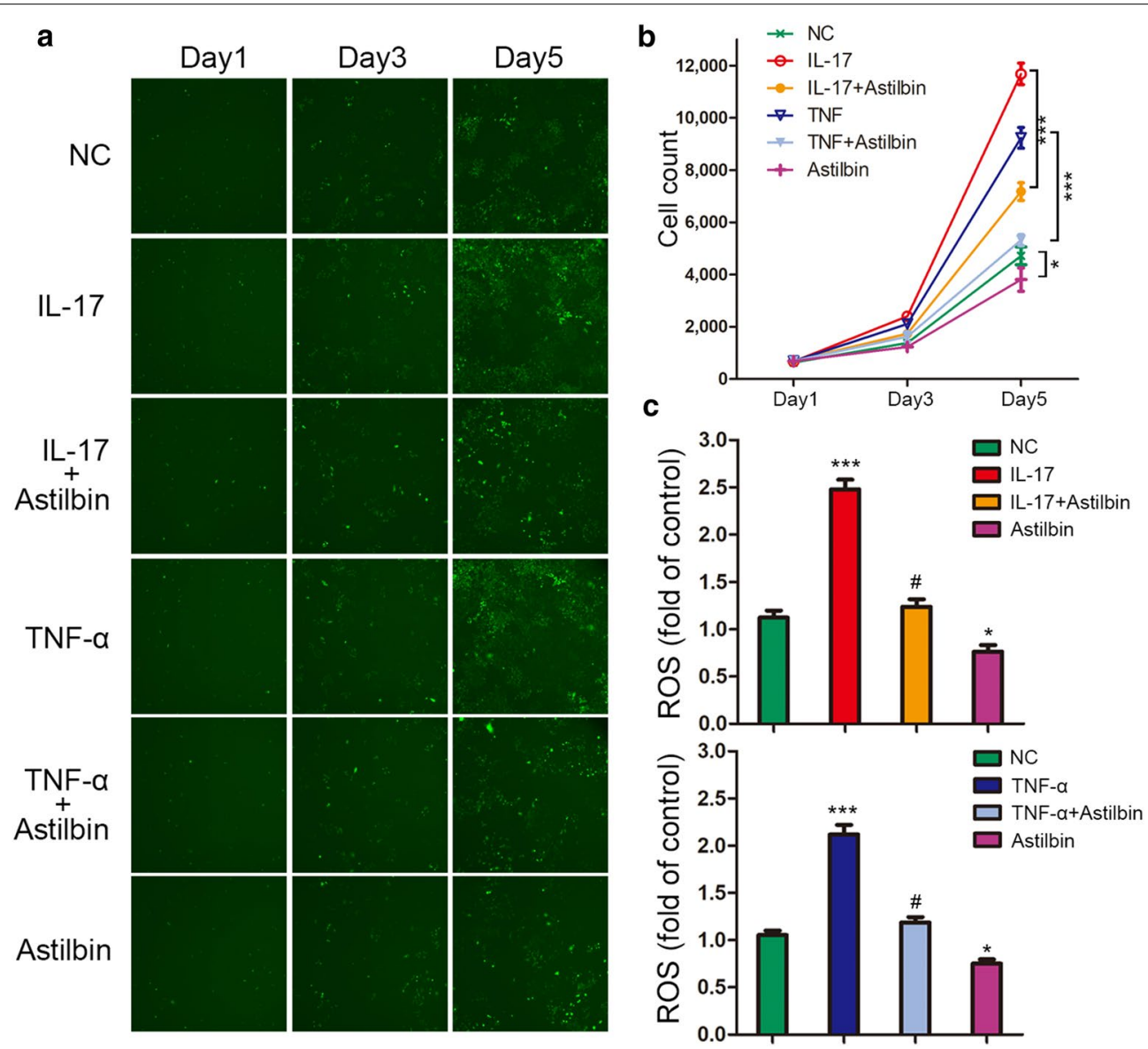

Fig. 1 Effects of astilbin on the proliferation and ROS generation in HaCaT cells. a Representative pictures of HaCaT cells treated with astilbin and pro-inflammatory cytokines via HCS for day1, day3 and day5. b Cell count of HaCaT cells via HCS for day 1, day 3 and day5. ${ }^{* P}<0.05 ; *^{* * P}<0.001$. c Quantification and statistical analysis of ROS-positive cells. ${ }^{*} \mathrm{P}<0.05$ and ${ }^{* *} \mathrm{P}<0.001$ vs NC group; ${ }^{\# P}<0.05$ vs IL-17 or TNF-a group 


\section{Astilbin enhances Nrf2 activation under pro-inflammatory} cytokines stress

To identify further the mechanisms of astilbin-exhibited reduction of ROS generation, the expression and the localization of Nrf2 was detected under the stimulation of IL-17 and TNF- $\alpha$. We found that IL-17 and TNF- $\alpha$ could increase the Nrf2 expression, however, the two cytokines had little effects on the accumulation of Nrf2 in the nuclei. Treatment with astilbin significantly elevated the Nrf2 accumulation in the nuclei and reduce the expression in cytoplasm, which suggests that astilbin may promote the nuclear transfer of Nrf2 (Fig. 2a). In addition, the protein level of HO-1, an antioxidant protein regulated by $\mathrm{Nrf} 2$, was significantly up-regulated in the presence of astilbin, regardless of the previous stimulation with proinflammatory cytokine. Next, we examined the mRNA expression of AKR1C1, GCLM and GCLC, which are generally activated by the transcriptional regulation of Nrf2. Our results showed that astilbin increased AKR1C1, GCLM and GCLC mRNA levels in proinflammatory cytokine-stimulated $\mathrm{HaCaT}$ cells. These findings demonstrated that astilbin reduced ROS accumulation by enhancing Nrf2 activation.

\section{Astilbin attenuated the expression of VEGF by Nrf2 activation in $\mathrm{HaCaT}$ cells}

Angiogenesis is one of the pathological features of psoriasis. To investigate whether astilbin could have inhibitory effects on angiogenesis, we examined the protein and mRNA levels of vascular endothelial growth factor (VEGF) with astilbin treatment. The results suggested that astilbin significantly decreased the mRNA and protein levels of VEGF (Fig. 3a). We next explored the role of
NRF2 in the down-regulation of VEGF by astilbin. Three pairs of NFE2L2-siRNA were used to knock down Nrf2 expression in $\mathrm{HaCaT}$ cells. Western blot analysis showed that siNFE2L2-B could effectively silence the expression of Nrf2 (Fig. 3b). Then, we analyzed protein levels of VEGF in Nrf2 knockdown HaCaT cells. We found that astibilin did not altered VEGF expression in NRf2 knockdown $\mathrm{HaCaT}$ cells (Fig. 3c). Furthermore, Nrf2 inhibition annulled the inhibitory effect of astilbin on the proliferation of HaCaT cells (Fig. 3d).

To investigate whether astilbin has a beneficial effect on psoriasis, we administered astilbin to a mouse model of psoriasis. Topical application of imiquimod (IMQ) was used to establish the model. One intragastric administration of astibilin was introduced in two groups: one with low dose (astibilin $10 \mathrm{mg} / \mathrm{kg}$ ), and one with high dose $(50 \mathrm{mg} / \mathrm{kg}$ astilbin). The severity of psoriasis was determined according to the PASI (the Psoriasis Area and Severity Index) score at day20 (Table 1) and the phenotypical presentation photos of the mice back skin are shown in Fig. 3e. HE staining revealed that IMQ increased epidermal hyperplasia, acanthosis in the epidermis and perivascular infiltration of the inflammatory cells in the upper dermis, which corresponds with the pathological characteristic of psoriasis lesions. However, the lesions significantly resolved with astilbin administration, which was corroborated by a decrease in the thickness of the epidermis layer, which attenuated IMQinduced psoriasis (Fig. 3f). We also detected the expression of VEGF in the skin. Immunohistochemical staining for VEGF also revealed that that administration of astilbin decreased the number of VEGF positive cells in IMQinduced psoriasis (Fig. 3f and Table 2). Taken together,
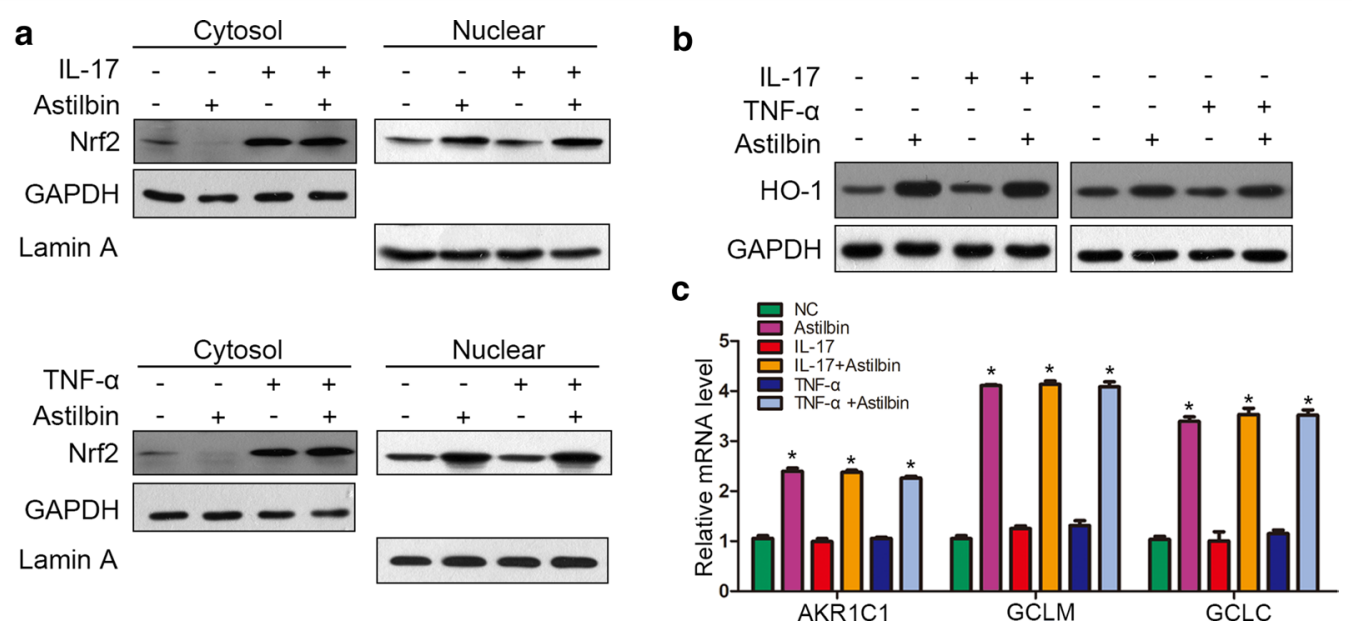

Fig. 2 Effects of astilbin on NRF2 activation. a The nuclear and cytoplasmic protein expression of NRF2 were determined using Western blot analysis. $\mathbf{b}$ The expression of HO-1 was determined using Western blot analysis. c mRNA levels of AKR1C1, GCLM and GCLC were evaluated using qPCR analysis. *P $<0.05$ vs NC group 
a
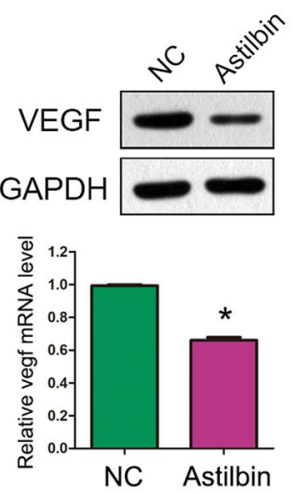

e

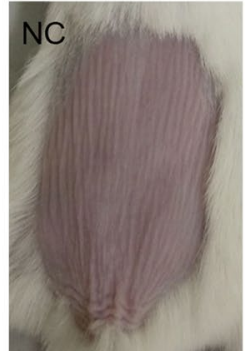

b

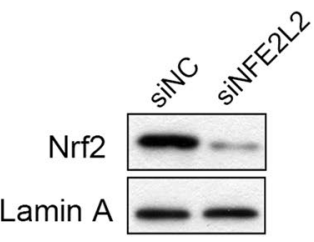

C

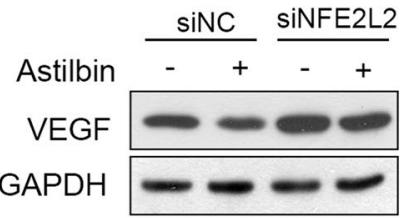

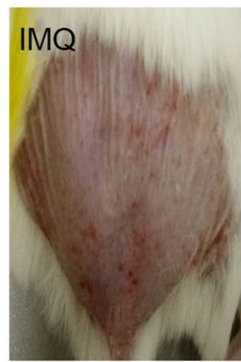

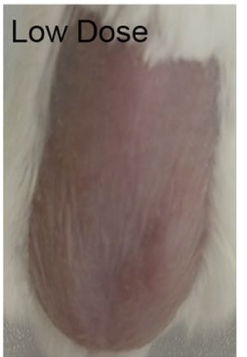

d
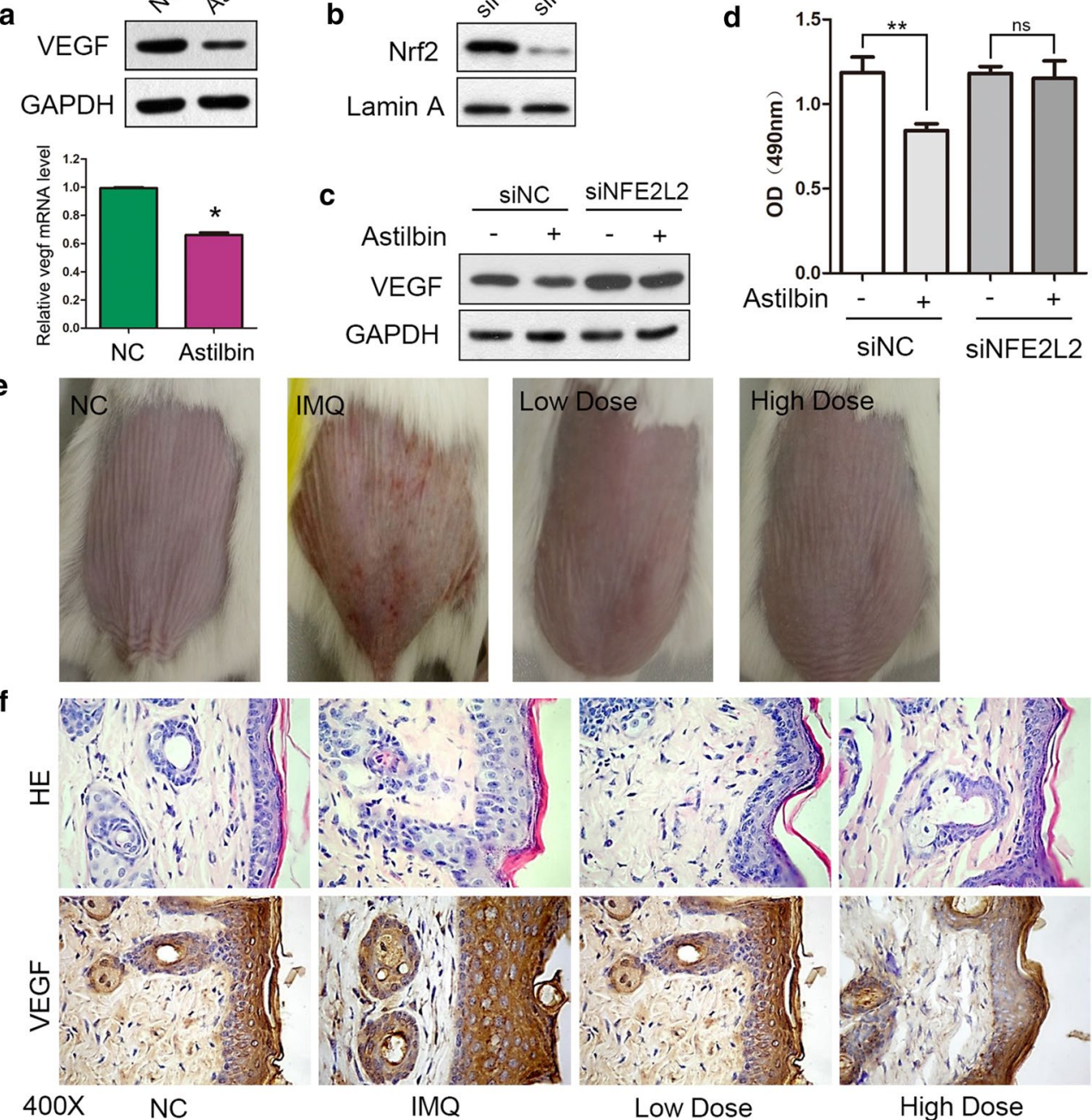

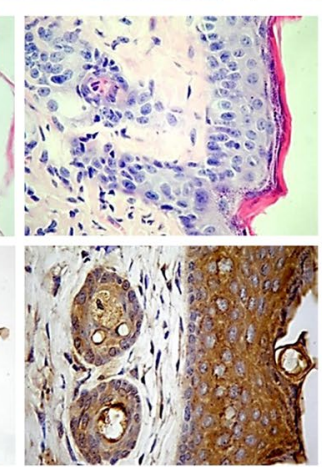

IMQ

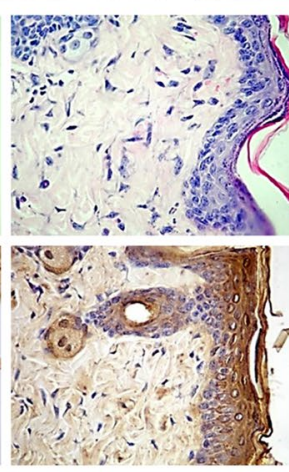

Low Dose

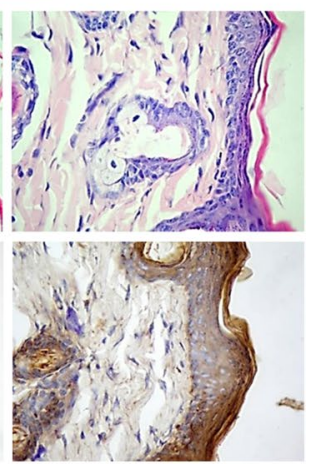

High Dose

Fig. 3 Astilbin attenuated the expression of VEGF. a The protein and mRNA level of VEGF were detected by Western blot and qPCR analysis, ${ }^{*} \mathrm{P}<0.05$ vs NC group. $\mathbf{b}$ Cells were transfected with $10 \mathrm{nM}$ of si-NFE2L2-B or si-NC, the level of Nrf2 was measured by Western blot analysis. c The expression of VEGF were measured by Western blot analysis under treatment with astilbin in Nrf2 knock-down HaCaT cells. $\mathbf{d}$ MTT assays showing the effect of Nrf2 knock-down on cell viability under astilbin treatment. ${ }^{*} \mathrm{P}<0.005 ; \mathrm{ns}$ no significance. $\mathbf{e}$ The phenotypical presentation of the mice back skin. f Psoriasis-like skin lesions were stained with HE, VEGF antibody. IMQ imiquimod; Low dose, 10 mg/kg; high dose, 50 mg/kg

Table 1 PASI score at day 20

\begin{tabular}{lllll}
\hline Group & $\begin{array}{l}\text { Erythema } \\
\mathbf{n}=\mathbf{1 0}\end{array}$ & $\begin{array}{l}\text { Induration } \\
\mathbf{n}=\mathbf{1 0}\end{array}$ & $\begin{array}{l}\text { Desquamation } \\
\mathbf{n}=\mathbf{1 0}\end{array}$ & PASI \\
\hline NC & 0 & 0 & 0 & 0 \\
IMQ & $2.2 \pm 0.42$ & $2.1 \pm 0.32$ & $2.2 \pm 0.42$ & $6.5 \pm 0.71^{*}$ \\
Low dose & $1.8 \pm 0.42$ & $1.7 \pm 0.48$ & $1.8 \pm 0.42$ & $5.3 \pm 0.48^{\#}$ \\
High dose & $1.5 \pm 0.53$ & $1.4 \pm 0.52$ & $1.5 \pm 0.53$ & $4.4 \pm 0.70^{\#}$ \\
\hline
\end{tabular}

${ }^{*} \mathrm{P}<0.05$ compared with $\mathrm{NC}$ group

\# $\mathrm{P}<0.05$ compared with IMQ group
Table 2 VEGF expression in IMQ-induced psoriasis

\begin{tabular}{lllll}
\hline Item & $\begin{array}{l}\mathrm{NC} \\
\mathbf{n}=\mathbf{1 0}\end{array}$ & $\begin{array}{l}\text { IMQ } \\
\mathbf{n}=1 \mathbf{0}\end{array}$ & $\begin{array}{l}\text { Low dose } \\
\mathbf{n}=1 \mathbf{0}\end{array}$ & $\begin{array}{l}\text { High dose } \\
\mathbf{n}=10\end{array}$ \\
\hline VEGF & $0.942 \pm 0.087$ & $6.329 \pm 0.437^{*}$ & $4.112 \pm 0.259^{\#}$ & $1.307 \pm 0.124^{\#, \wedge}$ \\
\hline${ }^{*} \mathrm{P}<0.05$ compared with $\mathrm{NC}$ group & & \\
$\# \mathrm{P}<0.05$ compared with IMQ group & & \\
$\wedge \mathrm{P}<0.05$ compared with low dose group & &
\end{tabular}


these results demonstrate that administration of astilbin efficiently suppresses the expression of VEGF in vivo and vitro, probably through enhancing NRF2 activation.

\section{Discussion}

Psoriasis is a chronic skin disease characterized by scaling, thickening and erythema of the skin, which is probably the most prevalent immune-mediated skin disease in adults [25]. Recent studies show that some mutations may lead to an abnormally increased activity of the immune system and, consequently, to increased inflammation and accompanying oxidative stress [26]. The endogenous antioxidant defence system of the body fails to replenish the damage, and the unfavourable skin metabolism further worsens the situation for patients with psoriasis [7]. It has also been suggested that generation of ROS from keratinocytes and fibroblasts can contribute to neutrophil activation, which plays an important role in psoriatic process $[27,28]$.

It is reported that astilbin from Smilax glabra Roxb. had protective effect on lead-induced oxidative stress [29], so we speculated that the antioxidant effect of astilbin could ameliorate the progression of psoriasis. Consequently, our results demonstrated that astilbin could reduce ROS generation and inhibit the proliferation of $\mathrm{HaCaT}$ cells. In addition, astilbin could elevate the Nrf2 accumulation in the nuclei to enhance its transcription factor activity, eventually leading to the transcriptional activation of various antioxidant proteins and even reducing the expression of VEGF. Therefore, we suggest that antioxidants, like astibilin, might act as a new therapeutic approach in psoriasis.

$\mathrm{Nrf2}$, a transcription factor of the cap " $\mathrm{n}$ " collar family, is a crucial regulator involved in cellular resistance to oxidants [30]. Intracellular ROS levels are regulated by an inducible antioxidant program that responds to cellular stressors and is largely correlated with the activation of Nrf2, which regulates the expression of multiple cytoprotective genes to counteract oxidative stress [31, 32]. Altered antioxidant response of Nrf2 increases the susceptibility to chemically induced skin cancer [33], and the inflammation of the skin lesion would be prolonged when its antioxidant effect is impaired [34]. Therefore, targeting the regulation of NRF2 activation can be contribute to prevent the risk of oxidative stress-related skin lesion. A recent study demonstrated that natural flavonoids can increase the expression of protective genes through activation of Nrf2. Although the effect of astilbin on Nrf2 in cisplatin-induced acute nephrotoxicity model has been reported [35], the underlying mechanism was still unknown. In this study, we explored the effect of astilbin on ROS accumulation and found astilbin strongly induced $\mathrm{Nrf2}$ nucleus translocation to stimulate the expression of Nrf2-mediated antioxidant genes in
$\mathrm{HaCaT}$ cells, suggesting that increasing the activation of Nrf2 may contribute to antioxidant effect of astilbin on keratinocyte cells line.

Vessel hyperplasia is one of the characteristics of psoriatic lesions. Vascular endothelial growth factor (VEGF) can be secreted by keratinocytes and is assumed to be involved in the pathogenesis of psoriasis [36]. Recent evidence indicated that the chronic administration of VEGF to the skin can result in development of psoriasis-like inflammation [37]. In the present study, we found that astilbin could reduce the expression of VEGF. However, astilbin was ineffective when Nrf2 was silenced, suggesting that astibilin effect in VEGF expression is dependent of Nrf2 activation and nuclear translocation.

\section{Conclusions}

In conclusion, our data suggested that astilbin could reduce the ROS accumulation and down-regulate the expression of VEGF by inducing Nrf2 nucleus translocation, which finally contributes to reduce the proliferation of $\mathrm{HaCaT}$ cells. Future studies may focus on the molecular mechanisms by which astilbin inhibits inflammation through Nrf2 activation.

\section{Method}

\section{Cell lines and treatment}

The HaCaT cell line were obtained from the Cell Bank of Type Culture Collection of Chinese Academy of Sciences (Shanghai, China). HaCaT cells were cultured in Dulbecco's Minimum Essential Medium supplemented with $10 \%$ fetal bovine serum at $37^{\circ} \mathrm{C}$ in a humidified atmosphere containing $5 \% \mathrm{CO}_{2}$. All of the culture media were purchased from Sigma (St. Louis, MO, USA), and fetal bovine serum was purchased from Gibco (catalogue no. 16000-044; Grand Island, NY, USA). IL-17A and TNF- $\alpha$ were purchased from Abcam (IL-17A, ab9567; TNF$\alpha$, ab9642). Cells were cultured to $80 \%$ confluence and incubated with IL-17A $(50 \mathrm{ng} / \mathrm{ml})$ or TNF- $\alpha(10 \mathrm{ng} / \mathrm{ml})$ for $24 \mathrm{~h}$. Astilbin was purchased from Ourchem Sinopharm Chemical Reagent (CAS\#: 29838-67-3, XW080058) and was dissolved in dimethyl sulfoxide (DMSO, Beyotime, ST038) at a concentration of $10 \mathrm{mM}$ and stored at $-20{ }^{\circ} \mathrm{C}$.

\section{High-content screening cell proliferation assay}

Cell growth was measured via multiparametric highcontent screening (HCS). After $72 \mathrm{~h}$ of infection with the $\mathrm{NC}$ lentivirus, $\mathrm{HaCaT}$ cells were re-suspended, counted and inoculated into 96-well plates. With the treatment of astilbin for 1 day, 3 day and 5 day, the proliferation of the cells in each of the wells was analysed daily using Metaxpress HCS software (Molecular Devices). The system uses a computerized, automated fluorescence imaging 
microscope that automatically identifies stained cells and measures the intensity and distribution of fluorescence in each individual cell.

\section{ROS detection}

Intracellular ROS levels were evaluated by $2^{\prime}, 7^{\prime}$-dichlorodihydrofluorescein diacetate (DCFH-DA, Sigma Aldrich, D6883) staining assay, the $\mathrm{HaCaT}$ cells were incubated with DCFH-DA $(10 \mu \mathrm{M})$ according to the manufacturer's instructions. The fluorescence was measured using flow cytometry (C6, Millipore).

\section{Western blotting}

Cytoplasmic and nuclear extracts were prepared according to the instructions of the NE-PER Nuclear and Cytoplasmic Extraction kit (Thermo Scientific, 78833). Samples from cell lysates were separated by SDS-polyacrylamide gel electrophoresis, transferred onto polyvinylidene difluoride membranes, and incubated with primary antibodies, including: Nrf2 (1:1000; Abcam, ab137550), HO-1 (1:1000; Abcam, ab68477), VEGF (1:1000; Proteintech, 19003-1-AP), Lemin A (1:1000; Cell Signaling, 86846s), and GAPDH (1:2000; Cell Signaling, 5174 s), followed by incubation with horseradish peroxidase (HRP)-conjugated secondary antibody (1:2000; Cell Signaling, 7074v/70). Protein expression was visualized by enhanced chemiluminescence assay.

\section{Quantitative real-time PCR}

Total RNA was isolated from frozen tissues and cell lines using TRIzol (Invitrogen, USA), according to the manufacturer's instructions. RNA was used for the first-strand cDNA synthesis with a Takara RNA PCR Kit (Takara). Real-time PCR was performed using SYBR Green Premix Ex Taq Ver. 3.0 (Takara) and detected by StepOne plus. GAPDH was used as an internal control. The primers used were as follows: AKR1C1 forward, 5'-TGGGAGGCCGTG GAGAA-3'; AKR1C1 reverse, 5'-GGACACCCCGAT GGACCTG-3'; GCLM forward, 5'-ACAGGTAAAACC AAATAGTAACCAAGTTAA-3'; GCLM reverse, 5'-TGT TTAGCAAATGCAGTCAAATCTG-3'; GCLC forward, 5'-GATGCTGTCTTGCAGGGAATG-3'; GCLC reverse, 5'-AGCGAGCTCCGTGCTGTT-3'; GAPDH forward, $5^{\prime}$-AAGGTCGGAGTCAACGGATTTG-3'; and GAPDH reverse, 5'-CCATGGGTGGAATCATATTGGAA- ${ }^{\prime}$.

\section{siRNAs and transfection}

The targeting sequence for Nrf2 siRNA was: NFE2L2B, 5'-AAUUCCAAGUCCAUCAUGCUG-3' (sense), $5^{\prime}$-GCAUGAUGGACUUGGAAUUGC-3' (antisense).
Transfection of siRNA into $\mathrm{HaCaT}$ cells was carried out using Lipofectamine 2000 (Invitrogen, Carlsbad, CA, USA) following the manufacturer's instructions.

\section{Mouse studies}

Six-week-old male BALB/c mice were purchased from Changchun Yisi Laboratory Animal Center. All experimental procedures involving mice were in compliance with the National Institutes of Health Guide for the Care and Use of Laboratory Animals and were approved by the Review Committee for the Use of Animals of Inner Mongolia University for Nationalities. Mice were topically treated with IMQ cream (China Meheco Keyi Pharma Co., Ltd, H20040285) on the shaved back skin $(2 \mathrm{~cm} * 2 \mathrm{~cm})$ once a day for 7 days to induce a psoriasislike dermatitis. Different doses of astilbin were selected for intragastric administration at day7, once a day for 13 days. The mice were sacrificed after 20 days, and the back skin were harvested. According to the PASI scoring standard, erythema (redness), induration (thickness) and desquamation (scaling) are scored as 0 to 4 in the skin lesions, and intensity scores are added up for the total score. The intensity of redness, thickness and scaling of the psoriasis is assessed as none (0), mild (1), moderate (2), severe (3) or very severe (4).

\section{Immunohistochemistry}

Standard protocols were used to prepare tissue microarray sections for immunohistochemistry. Then sections were blocked by UltraVision Hydrogen Peroxide Block (Thermo Scientific, CA, USA) and UltraVision Protein Block (Thermo Scientific), followed by primary antibodies (VEGF, 1:100) incubation. UltraVision Quanto Detection System horseradish peroxidase (HRP) Polymer (Thermo Scientific) and DAB Quanto (Thermo Scientific) were applied for staining, and hematoxylin was used for counterstaining. The score of erythema, scale and infiltration thickening of the skin lesions in mice was scored as 0 to 4: 0 , negative; 1 , weak; 2 , moderate; 3 , strong; and 4 very strong. Add the three scores to get the total points, taking the average of the scores of the mice in each group, and skin lesions in each group were observed.

\section{Statistical analysis}

Analysis was performed with SPSS software, version 22.0 (SPSS, Chicago, IL, USA). The data are presented as the mean \pm standard deviation, with at least three replicates used for each data point. Differences between two groups were analyzed with Student's $t$ test. Statistical significance was determined at the level of $\mathrm{P}<0.05$. 


\section{Abbreviations}

ROS: reactive oxygen species; VEGF: vascular endothelial growth factor; Nrf2 or NFE2L2: Nuclear factor (erythroid-derived 2)-like 2; IL-17: interleukin-17; TNF-a: tumour necrosis factor a; HCS: high-content screening; DCFH-DA: 2',7'-dichlorodihydrofluorescein diacetate; HO-1: heme oxygenase 1; AKR1C1: Aldo-keto reductase family 1 member $\mathrm{C}$; GCLM: glutamate-cysteine ligase regulatory subunit; GCLC: glutamate-cysteine ligase catalytic subunit; IMQ: imiquimod.

\section{Acknowledgements}

Not applicable.

\section{Authors' contributions}

WW designed the study and drafted the manuscript. HY and GB contributed materials and helped to review the manuscript. WW, HW and SC coordinated to perform the experiments and analyze the data. All authors read and approved the final manuscript.

\section{Funding}

This work was supported by grants from Science Research Project of Inner Mongolia Higher Educational System (NJZZ18155), Scientific Research Foundation of Affiliated Hospital of Inner Mongolia University for Nationalities (2017QDJJ08).

\section{Availability of data and materials}

All data generated or analysed during this study are included in this published article.

\section{Ethics approval and consent to participate}

This study was approved by the Ethics Committee of Inner Mongolia University for Nationalities, and the written informed consent was also obtained from each participant in advance.

\section{Consent for publication}

Not applicable.

\section{Competing interests}

The authors declare that they have no competing interests.

\section{Author details}

${ }^{1}$ Department of Mongolian Pharmacy, School of Mongol Medicine, Inner Mongolia University for Nationalities, 536 West of Huolinhe Street, Tongliao 028000, Inner Mongolia, People's Republic of China. ${ }^{2}$ Department of Dermatology, Affiliated Hospital of Inner Mongolia University for Nationalities, Tongliao, Inner Mongolia, People's Republic of China. ${ }^{3}$ Library of Inner, Mongolia University for Nationalities, Tongliao, Inner Mongolia, People's Republic of China.

Received: 11 February 2019 Accepted: 13 August 2019

Published online: 06 September 2019

\section{References}

1. Ben Salem C, Hmouda H, Bouraoui K. Psoriasis. N Engl J Med. 2009;361(17):1710 (author reply 1710).

2. Haneke E. Nail psoriasis: clinical features, pathogenesis, differential diagnoses, and management. Psoriasis. 2017:7:51-63.

3. Mehta NN, Krishnamoorthy P, Yu Y, Khan O, Raper A, Van Voorhees A, Troxel AB, Gelfand JM. The impact of psoriasis on 10-year Framingham risk. J Am Acad Dermatol. 2012;67(4):796-8.

4. Praveenkumar U, Ganguly S, Ray L, Nanda SK, Kuruvila S. Prevalence of metabolic syndrome in psoriasis patients and its relation to disease duration: a hospital based case-control study. J Clin Diagn Res. 2016;10(2):WC01-5.

5. Sanchez-Carazo JL, Lopez-Estebaranz JL, Guisado C. Comorbidities and health-related quality of life in Spanish patients with moderate to severe psoriasis: a cross-sectional study (Arizona study). J Dermatol. 2014:41(8):673-8.

6. Lowes MA, Bowcock AM, Krueger JG. Pathogenesis and therapy of psoriasis. Nature. 2007:445(7130):866-73.
7. Baz K, Cimen MY, Kokturk A, Yazici AC, Eskandari G, Ikizoglu G, Api H, Atik U. Oxidant/antioxidant status in patients with psoriasis. Yonsei Med J. 2003:44(6):987-90

8. Holmdahl R, Sareila O, Olsson LM, Backdahl L, Wing K. Ncf1 polymorphism reveals oxidative regulation of autoimmune chronic inflammation. Immunol Rev. 2016;269(1):228-47.

9. Gabr SA, Al-Ghadir AH. Role of cellular oxidative stress and cytochrome $\mathrm{c}$ in the pathogenesis of psoriasis. Arch Dermatol Res. 2012;304(6):451-7.

10. Ambrozewicz E, Wojcik P, Wronski A, Luczaj W, Jastrzab A, Zarkovic N, Skrzydlewska E. Pathophysiological alterations of redox signaling and endocannabinoid system in granulocytes and plasma of psoriatic patients. Cells. 2018;7(10):159.

11. Hasse-Cieslinska M, Dmochowski M, Bowszyc-Dmochowska M, Silny W, Danczak-Pazdrowska A. A case of sporadic pemphigus foliaceus in teenage girl with psoriasis vulgaris. Polski merkuriusz lekarski: organ Polskiego Towarzystwa Lekarskiego. 2005;18(107):568-70.

12. Ma Q. Role of nrf2 in oxidative stress and toxicity. Annu Rev Pharmacol Toxicol. 2013;53:401-26.

13. Loboda A, Damulewicz M, Pyza E, Jozkowicz A, Dulak J. Role of Nrf2/HO-1 system in development, oxidative stress response and diseases: an evolutionarily conserved mechanism. Cell Mol Life Sci. 2016;73(17):3221-47.

14. Lee YJ, Bae JH, Kang SG, Cho SW, Chun DI, Nam SM, Kim CH, Nam HS, Lee $\mathrm{SH}$, Lee $\mathrm{SH}$, et al. Pro-oxidant status and Nrf2 levels in psoriasis vulgaris skin tissues and dimethyl fumarate-treated $\mathrm{HaCaT}$ cells. Arch Pharmacal Res. 2017:40(9):1105-16.

15. Zhang J, Li X, Wei J, Chen H, Lu Y, Li L, Han L, Lu C. Gallic acid inhibits the expression of keratin 16 and keratin 17 through $\mathrm{Nrf} 2$ in psoriasis-like skin disease. Int Immunopharmacol. 2018;65:84-95.

16. Zhang QF, Fu YJ, Huang ZW, Shangguang XC, Guo YX. Aqueous stability of astilbin: effects of $\mathrm{pH}$, temperature, and solvent. J Agric Food Chem. 2013;61(49):12085-91.

17. Zheng D, Zhang L, Zhang QF. Isomerization of astilbin and its application for preparation of the four stereoisomers from Rhizoma Smilacis Glabrae. J Pharm Biomed Anal. 2018;155:202-9.

18. Zou W, Zhou H, Hu J, Zhang L, Tang Q, Wen X, Xiao Z, Wang W. Rhizoma Smilacis Glabrae inhibits pathogen-induced upper genital tract inflammation in rats through suppression of NF-kappaB pathway. J Ethnopharmacol. 2017:202:103-13.

19. Jiang J, Xu Q. Immunomodulatory activity of the aqueous extract from rhizome of Smilax glabra in the later phase of adjuvant-induced arthritis in rats. J Ethnopharmacol. 2003;85(1):53-9.

20. Wang M, Zhao J, Zhang N, Chen J. Astilbin improves potassium oxonateinduced hyperuricemia and kidney injury through regulating oxidative stress and inflammation response in mice. Biomed Pharmacother. 2016;83:975-88

21. Xu WA, Yin $L$, Pan HY, Shi $L$, Xu L, Zhang $X$, Duan JA. Study on the correlation between constituents detected in serum from Rhizoma Smilacis Glabrae and the reduction of uric acid levels in hyperuricemia. J Ethnopharmacol. 2013:150(2):747-54.

22. Sa F, Gao JL, Fung KP, Zheng Y, Lee SM, Wang YT. Anti-proliferative and pro-apoptotic effect of Smilax glabra Roxb. extract on hepatoma cell lines. Chemico-Biol Interact. 2008;171(1):1-14.

23. Ronpirin C, Tencomnao T. Effects of the antipsoriatic drug dithranol on E2A and caspase-9 gene expression in vitro. Genet Mol Res. 2012;11(1):412-20.

24. Balato A, Lembo S, Mattii M, Schiattarella M, Marino R, De Paulis A, Balato N, Ayala F. IL-33 is secreted by psoriatic keratinocytes and induces pro-inflammatory cytokines via keratinocyte and mast cell activation. Exp Dermatol. 2012;21(11):892-4.

25. Asha K, Singal A, Sharma SB, Arora VK, Aggarwal A. Dyslipidaemia \& oxidative stress in patients of psoriasis: emerging cardiovascular risk factors. Indian J Med Res. 2017;146(6):708-13.

26. Di Meglio P, Villanova F, Nestle FO. Psoriasis. Cold Spring Harb Perspect Med. 2014. https://doi.org/10.1101/cshperspect.a015354

27. Akbulak O, Karadag AS, Akdeniz N, Ozkanli S, Ozlu E, Zemheri E, Oguztuzun S. Evaluation of oxidative stress via protein expression of glutathione S-transferase and cytochrome p450 (CYP450) isoenzymes in psoriasis vulgaris patients treated with methotrexate. Cutan Ocul Toxicol. 2018;37(2):180-5.

28. Rajappa M, Shanmugam R, Munisamy M, Chandrashekar L, Rajendiran KS, Thappa DM. Effect of antipsoriatic therapy on oxidative stress index and sialic acid levels in patients with psoriasis. Int J Dermatol. 2016:55(8):e422-30. 
29. Xia D, Yu X, Liao S, Shao Q, Mou H, Ma W. Protective effect of Smilax glabra extract against lead-induced oxidative stress in rats. J Ethnopharmacol. 2010;130(2):414-20.

30. Sykiotis GP, Bohmann D. Stress-activated cap'n'collar transcription factors in aging and human disease. Sci Signal. 2010;3(112):re3.

31. DeNicola GM, Karreth FA, Humpton TJ, Gopinathan A, Wei C, Frese K, Mangal D, Yu KH, Yeo CJ, Calhoun ES, et al. Oncogene-induced Nrf2 transcription promotes ROS detoxification and tumorigenesis. Nature. 2011:475(7354):106-9.

32. Zhang QY, Chu XY, Jiang LH, Liu MY, Mei ZL, Zhang HY. Identification of non-electrophilic Nrf2 activators from approved drugs. Molecules. 2017;22(6):883

33. Xu C, Huang MT, Shen G, Yuan X, Lin W, Khor TO, Conney AH, Kong AN. Inhibition of 7,12-dimethylbenz(a)anthracene-induced skin tumorigenesis in C57BL/6 mice by sulforaphane is mediated by nuclear factor E2-related factor 2. Cancer Res. 2006;66(16):8293-6.

34. Braun S, Hanselmann C, Gassmann MG, Auf Dem Keller U, Born-Berclaz C, Chan K, Kan YW, Werner S. Nrf2 transcription factor, a novel target of keratinocyte growth factor action which regulates gene expression and inflammation in the healing skin wound. Mol Cell Biol. 2002;22(15):5492-505.
35. Wang SW, Xu Y, Weng YY, Fan XY, Bai YF, Zheng XY, Lou LJ, Zhang F. Astilbin ameliorates cisplatin-induced nephrotoxicity through reducing oxidative stress and inflammation. Food Chem Toxicol. 2018;114:227-36.

36. Chiarini A, Dal Pra I, Pacchiana R, Menapace L, Zumiani G, Zanoni M, Armato U. Comano's (Trentino) thermal water interferes with the expression and secretion of vascular endothelial growth factor-A protein isoforms by cultured human psoriatic keratinocytes: a potential mechanism of its anti-psoriatic action. Int J Mol Med. 2006;18(1):17-25.

37. Ren X, Li J, Zhou X, Luo X, Huang N, Wang Y, Chen X, Wei Y. Recombinant murine interleukin 4 protein therapy for psoriasis in a transgenic VEGF mouse model. Dermatology. 2009;219(3):232-8.

\section{Publisher's Note}

Springer Nature remains neutral with regard to jurisdictional claims in published maps and institutional affiliations.
Ready to submit your research? Choose BMC and benefit from:

- fast, convenient online submission

- thorough peer review by experienced researchers in your field

- rapid publication on acceptance

- support for research data, including large and complex data types

- gold Open Access which fosters wider collaboration and increased citations

- maximum visibility for your research: over $100 \mathrm{M}$ website views per year

At BMC, research is always in progress.

Learn more biomedcentral.com/submissions 